\title{
Smallest U.S. Population Growth in History: More Deaths, Fewer Births, and Less Immigration
}

\author{
Kenneth M. Johnson
}

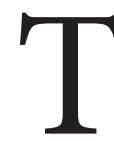
he U.S. population grew by just 393,000 between July of 2020 and July of 2021 according to new Census Bureau estimates-the lowest rate of annual population gain in history and the smallest numeric gain in more than 100 years. Diminished immigration from abroad contributed, but the driver of this minimal population gain was that there were only 148,000 more births than deaths. This is the smallest excess of births over deaths in more than 80 years and an 84 percent decline from just two years ago (Figure 1). Deaths reached a record high of 3,434,000, 20 percent more than two years ago. In contrast, there were just 3,582,000 births, the fewest since 1979 and a 5 percent decline from two years ago. Births declined even though there were more women of childbearing age.

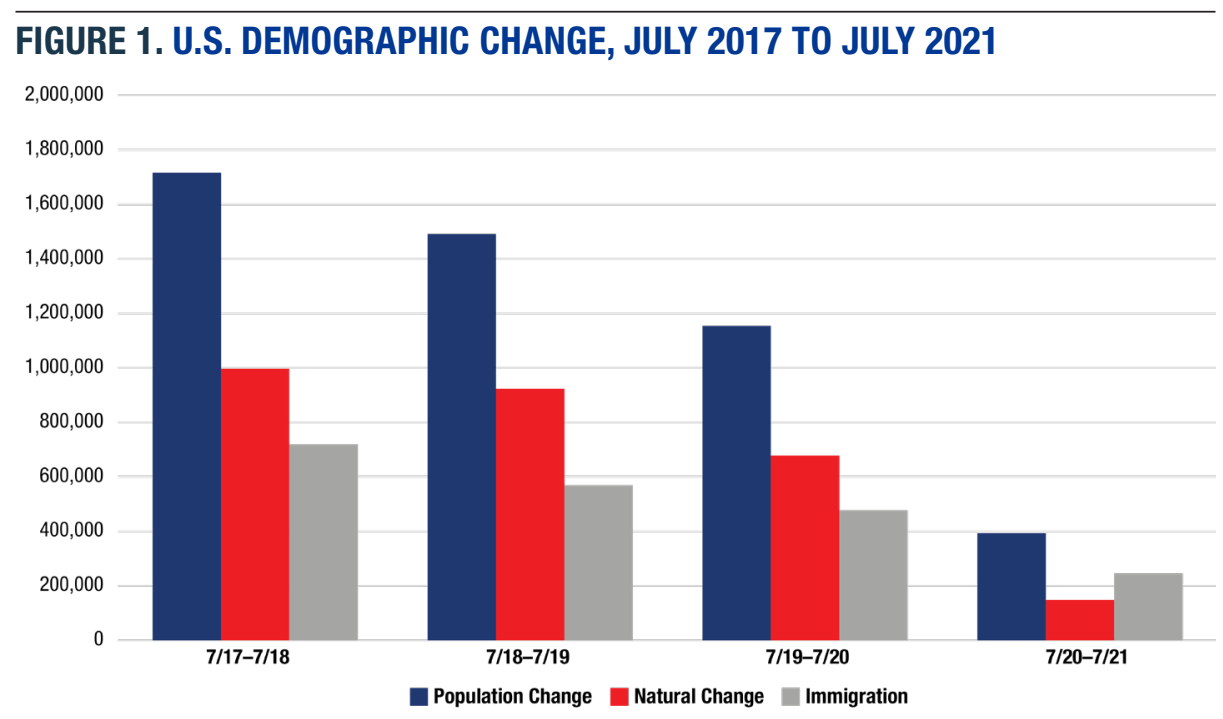

Source: Census Bureau Estimates. Analysis: K.M. Johnson, University of New Hampshire.

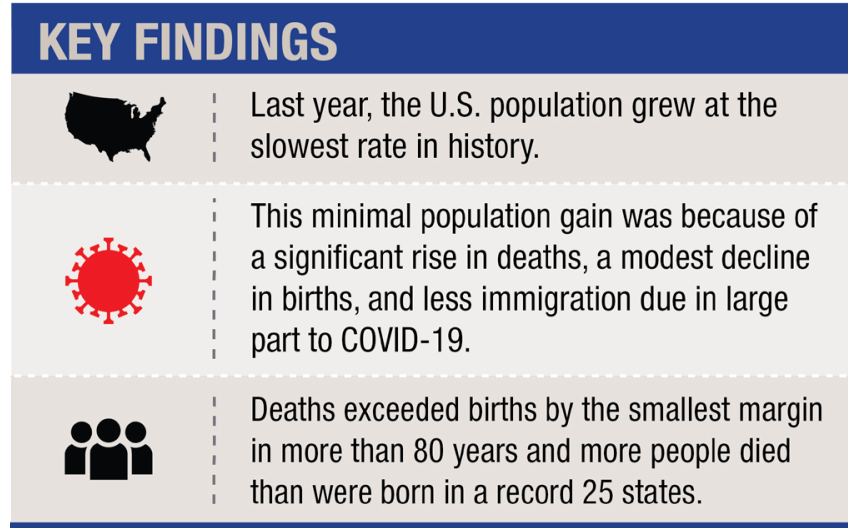

COVID-19 played a central role in this small population gain. In addition to 475,000 deaths directly attributable to COVID during the period, it also increased mortality by hindering people's access to treatment for other health conditions, discouraged people from having babies, and reduced immigration.

\section{Just 33 States Gained Population and Deaths Exceeded Births in a Record 25 States}

The demographic forces that diminished U.S. population growth also influenced state population change, though there is an important difference. While the nation's migration gain comes entirely from net immigration
Huddleston Hall • 73 Main Street • Durham, NH 03824 (603) 862-2821 • carsey.unh.edu
TTY USERS: DIAL 7-1-1 OR

1-800-735-2964 (RELAY N.H.) 
from other countries, state migration gains or losses also include domestic migration-people moving between states. Therefore, state population change depends on the balance between births and deaths, and the net movement of people into and out of the state both from immigration and domestic migration. In all, 33 states gained population last year compared to 37 two years ago. Fewer births and more deaths played an important role in this slowdown. Deaths exceeded births in 25 statesthe most in U.S. history. Among the 33 states that did gain population, 13 had both more births than deaths and a net inflow of migrants, and in 3 other states natural increase was sufficient to offset a migration loss (Figure 2). The population grew in 17 other states only because they gained enough migrants to offset a natural loss due to more deaths than births. Among the 18 states that lost population, 4 had both more deaths than births and a migration loss, and in 4 states the excess of death over births was greater than a migration gain. In the 10 remaining population-loss states there were more births than deaths, but not enough to offset a migration loss.

Looking ahead, the short-term prospects for substantial population increase appear limited. Over the past decade, the number of deaths has been growing, while the number of births has diminished. As a result, the excess of births over deaths was already dwindling before the onset of the pandemic. COVID-19 exacerbated these trends by significantly increasing mortality and further depressing fertility. Over the long term, mortality is likely to continue to rise among the aging U.S. population. Simultaneously, the decline in births, which began during the Great Recession, appears to be ongoing.

\section{FIGURE 2. POPULATION CHANGE, NATURAL CHANGE, AND NET MIGRATION BY STATE, JULY 2020 TO JULY 2021}

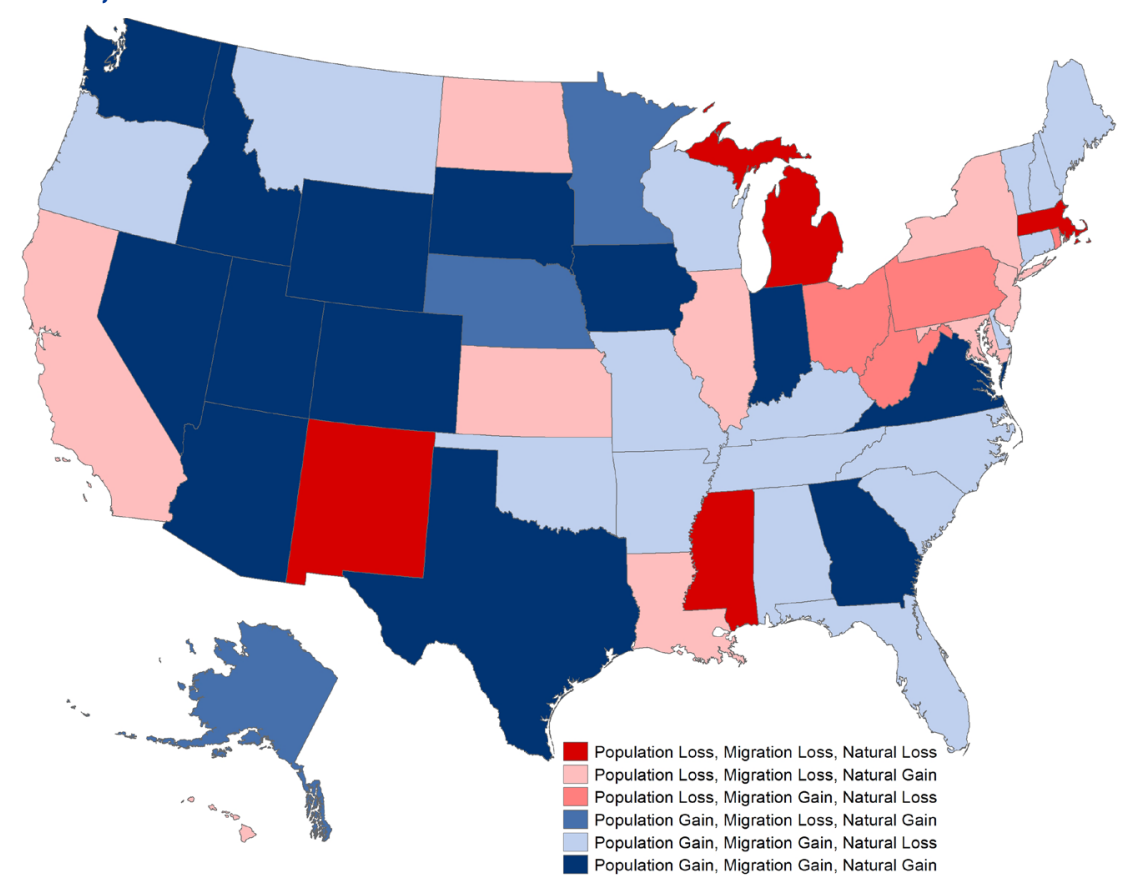

Source: Census Bureau Estimates. Analysis: K.M. Johnson, University of New Hampshire.

This leaves little likelihood of significant natural gain to fuel population growth. Immigration also remains at a low ebb. How protracted the additional fertility decline and mortality increases associated with COVID-19 will be, or what the prospects for immigration are, remains to be seen, but to date they have dramatically reduced population growth in the United States.

\section{Methods and Data}

This analysis is based on data from the Census Bureau Population Estimates Program released on December 21, 2021, covering July 1 , 2020 to June 30, 2021. The Census Bureau estimation algorithms use 2020 Census data, provisional birth and death data from the National Center for Health Statistics, and additional administrative data to estimate current demographic trends. Readers should recognize that although this analysis uses the best data available and is likely to be indicative of current trends, the data remain estimates. Concerns about both the quality of the 2020 Census and the impact of the Census Bureau's Differential Privacy algorithms on the accuracy of the 2020 Census remain unresolved.

\section{About the Author}

Kenneth M. Johnson is senior demographer at the Carsey School of Public Policy, professor of sociology at the University of New Hampshire, and an Andrew Carnegie Fellow. His research was supported by a UNH Faculty Scholar Award and by the New Hampshire Agricultural Experiment Station in support of Hatch MultiState Regional Project W-4001 through joint funding of the National Institute of Food and Agriculture, U.S. Department of Agriculture, under award number 1013434, and the state of New Hampshire. The opinions are his and not those of the sponsoring organizations. The research assistance of Kristine Bundschuh and GIS work of Barb Cook are gratefully acknowledged. 